\title{
A transdisciplinaridade nos processos do ensino e da aprendizagem no ensino fundamental
}

\author{
Ortenila Sopelsa*, Regina Oneda Mello**, Juliana Ansiliero***, Jaqueline Ferrari**** \\ *Professora e Pesquisadora do Programa de Mestrado em Educação da Unoesc, ** Professora da Graduação da Unoesc, \\ ***Mestranda e Professora do Ensino Fundamental na rede pública municipal, **** Graduanda de Psicologia da \\ Unoesc e bolsista do CNPq.
}

\section{RESUMO}

O estudo teve o objetivo de investigar como a Transdisciplinaridade pode contribuir nos processos do ensino e da aprendizagem. A pesquisa qualitativa, com abordagem participante, foi desenvolvida em uma escola pública municipal. Os sujeitos envolvidos foram as professoras do $5^{\circ}$ ano do Ensino Fundamental e seus respectivos alunos. Os dados foram coletados mediante grupo de estudos, entrevistas semiestruturadas, com a professora titular e $10 \%$ dos alunos e observação direta. Os resultados evidenciaram que o ensinar e o aprender ocorreram de forma articulada e contextualizada entre as diferentes disciplinas, ressignificando a aprendizagem dos alunos.

Palavras-chave: transdisciplinaridade, ensino, aprendizagem, ensino fundamental.

O presente artigo é parte de uma pesquisa que tem o objetivo de investigar como a trandisciplinaridade pode contribuir nos processos do ensino e da aprendizagem no Ensino Fundamental, com vistas a superar o conhecimento científico fragmentado e reduzido em diferentes disciplinas e especialidades. Diversos aspectos implicam nestes processos, como a diversidade e a quantidade de alunos em sala de aula; as políticas e sistemas de avaliação educacionais e, sobretudo, as ações pedagógicas que se desenvolvem no contexto escolar.

O paradigma reducionista da ciência moderna influenciou a educação em seus aspectos metodológicos de divisão das disciplinas que, ao longo do tempo, tornaram-se especializadas e perderam a relação de diálogo e complementaridade recíproca. Gradativamente, afastou a capacidade crítica e reflexiva de professores e alunos na compreensão global dos fenômenos e seus contextos.

A organização disciplinar, como descreve Morin (2010, p. 39), “[...] institui-se no século XIX, principalmente com a afirmação das universidades modernas, desenvolvendo-se posteriormente, no século XX, com o progresso da pesquisa científica." A disciplinaridade organiza-se em torno de disciplinas que determinam o campo de atuação e se esforçam para impor sua importância social sobre as demais.

Os alunos aprendem a conhecer os fenômenos e objetos isolando-os do todo, quando é necessário o inverso, religá-los à complexidade. Essa nova concepção exige pensar um modelo de ensino que introduza novas práticas pedagógicas que possam redefinir os currículos, a fim de garantir o diálogo constante entre as disciplinas, articulando os processos do ensino e da aprendizagem, de forma transdisciplinar.

A partir dos estudos teóricos desenvolvemos um projeto coletivo, com métodos e ações transdisciplinares, em uma Escola de Ensino Fundamental. Participaram a Gestora, a professora titular e os alunos do quinto ano e as professoras de Artes, Ensino Religioso, Educação Física e Inglês. Tivemos como pressuposto subsidiar teórica e metodologicamente os sujeitos envolvidos na pesquisa.

Nessa perspectiva, Nicolescu (1999, p. 29) enfatiza que "a formulação de métodos e ações transdisciplinares tem de estar de acordo com as novas definições do sujeito e do objeto que emergem da metodologia da transdisciplinaridade."

Segundo Morin (2010), é necessário caminhar para uma concepção mais enriquecida e transformada da ciência, em que se estabeleça a comunicação entre objeto e sujeito, entre antropossociologia e ciências naturais. Poder-se-ia, então, dar impulso à comunicação - e não à unificação - entre "fatos" e "valores". Para que tal comunicação seja possível, são necessários, por um lado, um pensamento capaz de refletir sobre os fatos e de organizá-los para deles obter conhecimento não só atomizado, mas também molar; e, por outro, um pensamento capaz de conceber o enraizamento dos valores numa cultura e numa sociedade.

Os projetos coletivos são uma metodologia adequada para a abordagem transdisciplinar, à medida que permitem o compartilhar do saber, valorizando cada sujeito envolvido e cada área de conhecimento em sua individualidade, oportunizando um ambiente que valoriza as interações e propicia uma experiência de aprendizado cooperativo e compartilhado, tendo em vista que "a ciência nunca teria sido ciência se não tivesse sido transdisciplinar." (MORIN, 2010, p. 135).

A coleta de dados ocorreu mediante entrevista semiestruturada com a professora titular e dez por cento dos alunos participantes; grupos de estudos, observação direta; planejamento e desenvolvimento de atividades de ensino, de forma coletiva e articulada entre as diferentes disciplinas.

A fim de preservar a identidade dos sujeitos envolvidos a professora titular está identificada por PT, a Gestora PG e os alunos com A1, A2 e sucessivamente.

A análise dos dados ocorreu a partir das entrevistas, grupos de estudos, observação e atividades práticas. A presente pesquisa está articulada ao projeto observatório

Financiamento PIBIC CNPq.

Ortenila Sopelsa, ortenila.sopelsa@unoesc.edu.br; Regina Oneda Mello, regina.mello@unoesc.edu.br;

Juliana Ansiliero, ju.ansiliero@hotmail.com; Jaqueline Ferrari, jaquelineferrari2801@gmail.com.

Selección y y peer-review bajo responsabilidad del Grupo de Investigación G000422-GIPDAE, Universidade da Coruña, España 
"Estratégias e Ações Multidisciplinares nas Áreas de Conhecimentos das Ciências Humanas, Ciências da Natureza e Linguagens, na Mesorregião do Oeste Catarinense: implicações na qualidade da educação básica - Sistema Integrado Capes - SICAPES/2013216", em desenvolvimento, no Programa de Mestrado em Educação da Unoesc.

\section{ATITUDE TRANSDISCIPLINAR: O ENSINAR E O APRENDER NA INTERLOCUÇÃO DE PROFESSORES E ALUNOS}

Ao referir-se à educação do futuro, Morin (2010, p. 48) assinala que é necessário promover grande remembramento dos conhecimentos oriundos das ciências naturais, "a fim de situar a condição humana no mundo, dos conhecimentos derivados das ciências humanas para colocar em evidência a multidimensionalidade e a complexidade humana." Segundo o autor, a contribuição da escola para a educação do indivíduo vai além da interdisciplinaridade e aponta para um caminho que transcende em seus limites e possibilidades,

As escolas precisam, como afirma Morin (2010), entender algumas distinções da prática pedagógica cotidiana como: distinguir e não separar, associar e interligar e não separar e isolar, complexificar e não simplificar. Essas distinções são importantes quando pensamos e refletimos as práticas pedagógicas. Alunos e professores precisam entender que o conhecimento não pode ser fragmentado e reduzido a disciplinas, mas associativo, interligado e complexo para favorecer o desenvolvimento de mentalidades estudantis críticas e emancipadas frente às questões sociais, políticas, éticas, científicas e econômicas. A compreensão do outro requer a consciência da complexidade humana. O planeta necessita em todos os sentidos, de compreensões mútuas, de novas mentalidades, que compreendam as múltiplas relações dos eventos.

A transdiciplinaridade surge como uma possibilidade destas mudanças necessárias porque articula os conhecimentos de forma a contribuir para a compreensão da realidade conjunta e complexa, em um pensamento organizador, que ultrapassa um mero somatório. Nesta cooperação é também um território de desenvolvimento da criatividade, no entrelaçamento das artes, das letras e das ciências para sua elaboração, sem eliminar as contradições.

Nicolescu (1999, p. 13) conceitua transdiciplinaridade como: “[...] a dualidade que opõe os pares binários: sujeito-objeto, subjetividade-objetividade, matériaconsciência, natureza-divino, simplicidadecomplexidade, reducionismo-holismo, diversidadeunidade."

Essa dualidade representa a relação entre o disciplinar e o transdisciplinar. Se forem articuladas as ciências, os processos de ensino e aprendizagem tornam-se unidos na percepção e elaboração de um conteúdo global e não unificado, associando prática e teoria, tornando-se um conjunto criativo e atrativo de conteúdos a serem trabalhados.

Para Severino (2011, p. 31), "É preciso dar-se conta de que os resultados desses complexos processos de construção do conhecimento decorrente da exploração de uma abordagem multidisciplinar, interdisciplinar e transdisciplinar, não se constituem apenas de um somatório de saberes que se acumulam. Estamos aqui diante de uma situação que o todo é maior que a soma das partes. Este é o sentido do transdisciplinar, em se tratando de conhecimento efetivamente produzido no processo da existência histórica dos homens, quer no seu cotidiano, quer nos seus esforços de expressão discursiva universalizada." Vale enfatizar, então, que o pensamento complexo liga-se à própria ideia de uma educação transdisciplinar, à medida que interliga as influências e as áreas de saber em um diálogo constante. Por isso, a educação e o conhecimento não podem ser entendidos como um processo linear com início, meio e fim, mas como um processo de construção, de conflito e de experiências que convergem entre si e possibilitam a superação do reducionismo educacional expresso nos currículos estruturados em disciplinas.

De acordo com Petraglia (1995, p. 50), "o pensamento complexo é responsável pela ampliação do saber. Se o pensamento for fragmentado e mutilador, as ações terão o mesmo rumo, tornando o conhecimento cada vez mais simplista e simplificador."

O processo educacional é complexo, movido pelos desafios contemporâneos de ligar e interligar áreas de saber, aparentemente distantes e divergentes. O paradigma contemporâneo de educação consiste no desafio de elaborar currículos e reformular práticas pedagógicas que deem conta da complexidade do conhecimento. $\mathrm{O}$ aluno precisa romper com o modelo de pensamento linear e reducionista e construir um modo de pensamento transdisciplinar, capaz de enfrentar os desafios modernos.

Assim, a escola precisa acompanhar o ritmo das mudanças que se operam em todos os segmentos que compõem a sociedade. O mundo está cada vez mais interconectado, interdisciplinarizado e complexo.

Partindo destas concepções, apresentamos a seguir parte da pesquisa realizada na escola supracitada relatando o desenvolvimento das atividades realizadas pelas professoras e alunos.

$\mathrm{Na}$ primeira entrevista feita com a professora titular abordamos as questões sobre as principais dificuldades que ela sentia em sala de aula e o que entendia por transdisicplinaridade. Em seu relato ela assinala "O mais complicado é estabelecer a articulação entre teoria e prática porque o livro didático dificulta o processo de ensinar e aprender".

Em relação à transdisciplinaridade a professora, declarou "ouvi algo sobre o tema, porém nunca li a respeito".

Por estas razões, iniciamos os estudos no grupo, pelos textos de Candau (2000), Severino (2011) e Morin (2010). Candau devido à importância dada em relação à articulação da teoria e a prática. Em Morin (2010) nos embasamos na analise que ele faz acerca da complexidade do ensinar e o aprender. $\mathrm{O}$ autor entende que só o pensamento complexo sobre uma realidade também complexa pode fazer avançar a reforma do pensamento na direção da contextualização, da articulação e da interdisciplinarização do conhecimento 
produzido pela humanidade. Para ele, "[...] a reforma necessária do pensamento é aquela que gera um pensamento do contexto e do complexo [...]. O pensamento contextual busca sempre a relação de inseparabilidade e as inter-retroações entre qualquer fenômeno e seu contexto, e deste com o contexto planetário (Morin, p. 23, 2010)."

A partir de vários encontros no grupo de estudos com a gestora da escola e a professora titular optamos em desenvolver a pesquisa a partir de um tema gerador, eleito pela escola: "Viva bem para fazer o bem: A arte de se bem viver em coletividade". Nesse sentido, cada professor organizou os conteúdos e atividades nas turmas com as quais trabalharia. A professora titular e os alunos do $5^{\circ}$ ano, sujeitos de nossa pesquisa, optaram em conhecer os contos e estórias do Sítio do Pica-Pau Amarelo, de Monteiro Lobato, para desenvolver os estudos. Todas as professoras da turma assumiram coletivamente o planejamento da intervenção pedagógica.

Muitas atividades foram desenvolvidas no decorrer da pesquisa, porém elegemos apenas algumas para o presente artigo. As referidas atividades foram desenvolvidas de maneira transdisciplinar.

Uma das atividades desenvolvidas foi situar o Sítio do Pica-Pau Amarelo, que fica em Taubaté - SP. A professora utilizou o aplicativo Google Earth, localizou em tempo real e com imagens do Sítio oportunizou aos alunos conhecer o que era apenas citado nas estórias. A partir de São Paulo, no próprio mapa, a professora situou os alunos no estado de Santa Catarina até chegar ao município de Joaçaba e localizar a escola.

Nesta atividade trabalharam em matemática, as medidas de distância como quilômetros que distanciam a escola do Sítio; em ciências, com a vegetação e os animais, além da produção de textos.

Após a atividade de conhecer o sítio, a professora iniciou o trabalho com os personagens, como a Tia Anastácia, cozinheira da família; a Dona Benta, proprietária do Sítio; o Visconde de Sabugosa, a espiga de milho sábia; a Narizinho e o Pedrinho, netos da Dona Benta; a Emília, boneca falante da Narizinho, e os demais personagens criados por Lobato.

Com o estudo de todos os personagens, os alunos escolheram a Emília como mascote da sala, mas foram incentivados a produzir outros personagens, de acordo com a preferência de cada um, usando os conhecimentos da matemática como unidades de medida e figuras geométricas.

A partir disso a professora planejou uma atividade extraclasse, para que em casa criassem personagens do Sítio do Pica-Pau Amarelo com o auxílio dos pais. Para criação dos personagens os alunos utilizaram desde materiais industrializados até produtos naturais, como espiga de milho, chuchu, batata e laranja. Ao retornarem à escola com os personagens prontos a professora oportunizou estudos de ciências, com frutas e legumes; estudos em matemática com as formas geométricas dos personagens e incluiu artes no processo de criação artística.

Em sequência, a professora organizou uma visitação ao Sítio Pica-Pau Verde, localizado na região da escola. O referido Sítio, além de uma vasta área verde, possui um museu com vários objetos desde o início do século passado, de uma família de imigrantes italianos. Juntamente com os objetos da família juntaram-se objetos de outras famílias, abrangendo o estado de SC. O Sítio também mantém animais de estimação, como cavalos, coelhos, avestruz, pavão, patos e outros. Há também árvores nativas de diferentes espécies.

Nesta visitação foram estudados diferentes conteúdos, em seus contextos, como a matemática. Segundo o A1: "O tamanho da árvore do cedro me impressionou, ela tem 80 anos e é uma das madeiras mais nobres." A4 relatou: "Com as árvores nativas aprendi conhecer de onde vem o chimarrão que minha mãe toma todos os dias. Também conheci a pitanga, a guabiroba e a cereja nativa."

$\mathrm{Na}$ visita ao museu o A3 observou: "Nos objetos do museu vi uma máquina de costura de 1920. Mostrei a foto para minha avó e ela falou que tinha uma igual e costurava com ela, para família e vizinhas."

O contato com diferentes espécies de animais fez com que os estudos em sala de aula fossem concretizados na experienciação. Nesse sentido, A2 assinala: "É diferente ver o sítio no mapa e estar aqui. No mapa não dá para ver como os animais são bonitos, o pato no lago, o coelho solto, o cavalo e o pavão". A8 relata: "Amo cavalos. Aprendi a média de vida dos cavalos e como cuidar para eles viverem mais." A9 aponta: "Aprendi que a gestação da coelha é de 28 a 30 dias. Não sabia que era tão pouco tempo."

Conforme salienta Morin (2010), as crianças aprendem a História, a Geografia, a Química e a Física, dentro de categorias isoladas, sem saber, ao mesmo tempo, que a História sempre se situa dentro de espaços geográficos e que cada paisagem geográfica é fruto de uma história terrestre.

De maneira geral, nas escolas, as crianças aprendem a conhecer os objetos isolando-os, quando seria preciso também recolocá-los em seu meio ambiente para melhor conhecê-lo, sabendo que todo ser vivo só pode ser conhecido na sua relação com o meio que o cerca, onde vai buscar energia e organização.

Segundo PT, ficou evidenciado que planejar as intervenções pedagógicas a partir de conteúdos articulados facilita a compreensão dos alunos e motiva a participação nas atividades. "A discussão de temas relacionados às questões ambientais, sociais e culturais, em visita técnica ao sítio, oportunizou-me compreender como os alunos percebiam os temas estudados e como construíram um olhar sistêmico entre os diferentes sujeitos envolvidos." (PT).

Nesse sentido, Ramos (2014) ressalta que a transdisciplinaridade engloba, transcende e articula diferentes disciplinas, reconhecendo o desconhecido e o inesgotável que estão presentes em todas elas, buscando encontrar seus pontos de interseção e um vetor comum. A forma de os alunos registrarem o observado e de questionar sobre o desconhecido evidenciou que concretizavam, de forma substantiva, conhecimentos com os quais haviam se ocupado.

Ainda, para associar os conteúdos de forma efetiva, a professora trabalhou o tema "Guloseimas da Tia Anastácia”, a cozinheira negra do Sítio. Os alunos 
pesquisaram as receitas que Tia Anastácia preparava, em quais momentos eram feitas e servidas no sítio. A atividade encerrou com a degustação do bolo de milho e do café. Durante toda a atividade houve discussões e estudos sobre ingredientes, quantidades, formas além de estudos sobre a diferença racial, tendo em vista que Tia Anastácia é negra. Chizzotti (2003) observa que a atitude participante pode estar caracterizada por uma partilha completa, duradoura e intensiva da vida e da atividade dos participantes, identificando-se com eles, como igual entre pares, vivenciando todos os aspectos possíveis da sua vida, das suas ações e dos seus significados.

A professora PT, em seus relatos, observou que a interlocução entre as disciplinas facilita o aprendizado. Segundo ela, a produção de textos foi significativa a partir das leituras e vivências. "A leitura, a interpretação e a produção de textos de gêneros diversos, oportunizaram aos alunos a compreensão de que há diferentes possibilidades de registrar o conhecimento. Que a matemática está no cotidiano, seja na história da Emília (Monteiro Lobato) ou na altura da árvore de espécie nativa e rara, como o cedro. Que a história e a geografia se articularam com a ciência e a tecnologia." (PT).

Nicolescu (1999, p. 65-66) destaca: "Do ponto de vista integrador, a transdisciplinaridade requer equilíbrio entre amplitude, profundidade e síntese. A amplitude assegura uma larga base de conhecimento e informação. A profundidade assegura o requisito disciplinar e/ou conhecimento e informação interdisciplinar para a tarefa a ser executada. A síntese assegura o processo integrador."

PT declarou ainda: "Quanto mais eu trabalhava para organizar as aulas mais eu aprendia, pois é necessário muita leitura e muito estudo. É preciso elaboração de um plano de ação que contemple todas as disciplinas. Conversas constantes entre nós, professores. Em Educação Física os alunos ensaiaram a "Dança da Emília" para o Dia da Família. Requer muito esforço, dedicação e conhecimento para pôr em prática a transdisciplinaridade, mas não é impossível de fazê-la acontecer.” Para Luck (2001, p. 68), “O estabelecimento de um trabalho de sentido transdisciplinar provoca, como toda ação a que não se está habituado, sobrecarga de trabalho, certo medo de errar, de perder privilégios e direitos estabelecidos. A orientação para o enfoque transdisciplinar na prática pedagógica implica romper hábitos e acomodações, implica buscar algo novo e desconhecido. É certamente um grande desafio."

A referida pesquisa foi de suma importância tanto para a escola quanto para nós pesquisadoras. Percebe-se, assim, a importância de a universidade estar mais presente nas ações do ensino básico.

\section{CONSIDERAÇÕES FINAIS}

Com essas ações a escola oportuniza ensino voltado para a consciência da complexidade humana. O respeito à diversidade e a todas as áreas de conhecimento, compreender principalmente, que as diferentes disciplinas fazem parte de uma cultura diversa. Isso implica o respeito pela transcendência interior e exterior.

A educação precisa dialogar com as situações cotidianas do aluno, não apenas como informação, mas problematizando e interligando as áreas do saber. A proposta de uma educação transdisciplinar capaz de orientar os currículos e as ações pedagógicas apresentase como uma alternativa não somente viável, mas fundamental para refletir as dinâmicas da sociedade.

A escola, como lugar legítimo de aprendizagem, produção e reconstrução de conhecimento, cada vez mais precisa acompanhar as transformações da ciência contemporânea, adotar e simultaneamente apoiar as exigências transdisciplinares que hoje participam da construção de novos conhecimentos.

A transdisciplinaridade é um movimento importante de articulação entre o ensinar e o aprender. Compreendida como formulação teórica e assumida enquanto atitude tem a potencialidade de auxiliar os educadores e as escolas na ressignificação do trabalho pedagógico em termos de currículo, de métodos, de conteúdo, de avaliação e nas formas de organização dos ambientes para a aprendizagem.

$\mathrm{O}$ trabalho com projetos transdisciplinares favorece um espaço de análise das práticas pedagógicas, no qual o conhecimento advém da troca de experiências, visando ao complemento de atividades a partir do trabalho coletivo. Ao se pensar o espaço escolar diferente do modelo da ciência moderna, no qual vigora o princípio da fragmentação, da divisão, da simplificação, da redução, tendo como consequência a descontextualização do agir pedagógico, surge a necessidade de refletir sobre a realidade para compreendê-la e, assim, poder promover as mudanças necessárias à aquisição de um conhecimento integrado à realidade do aluno.

\section{REFERÊNCIAS}

CANDAU, Vera Maria (Org.). Rumo a uma nova didática. 11. ed. Petrópolis: Vozes, 2000.

CHIZZOTTI, A. Pesquisa em ciências humanas e sociais. 6. ed. São Paulo: Cortez, 2003.

LUCK, H. Pedagogia da interdisciplinaridade. Fundamentos teórico-metodológicos. Petrópolis: Vozes, 2001.

MORIN, E. Ciência com consciência. 14. ed. Rio de Janeiro: Bertrand Brasil, 2010.

NICOLESCU, B. $O$ manifesto $d a$ transdisciplinaridade. Tradução Lúcia Pereira de Souza. São Paulo: Trion, 1999.

PETRAGLIA, I. C. Edgar Morin: a educação e a complexidade do ser e do saber. Petrópolis: Vozes, 1995. RAMOS, Conceição. Artes visuais e transdisciplinaridade na era da complexidade - uma prática pedagógica continuada. Revista Lusófona de Educação, 2014.

SEVERINO, A. J. O conhecimento pedagógico e a interdisciplinaridade: O saber como intencionalização da prática. 16. ed. São Paulo: Papirus, 2011. 